\title{
ENVIRONMENTAL APPLICATIONS OF ENZYMES
}

\author{
Jim A. Nicell, Ph.D., P.Eng. \\ Department of Civil Engineering and Applied Mechanics, McGill University, \\ 817 Sherbrooke Street West, Montreal, Quebec, Canada, H3A 2K6
}

\begin{abstract}
Enzymatic processes fall between the two traditional categories of chemical and biological treatment systems since they involve chemical reactions based on the action of biological catalysts. A variety of enzymes from plants and microorganisms have been reported to play important roles in an array of waste treatment applications. Before the full potential of enzymes may be realized, a number of significant issues remain to be addressed. These include: development of low-cost sources of enzymes in quantities that are required at the industrial scale; demonstration of the feasibility of utilizing the enzymes efficiently under the conditions encountered during wastewater treatment; characterization of reaction products and assessment of their impact on downstream processes or on the environment into which they are released; and identification of methods for the disposal of solid residues, among others.
\end{abstract}

\section{INTRODUCTION}

Extensive research and development work has been conducted in recent years to enable industrial, agricultural, municipal, and commercial facilities to reduce their impacts on the environment. In particular, the implementation of increasingly stringent standards for the discharge of wastes into the environment has necessitated the need for the development of alternative processes for the production of goods and for the treatment and disposal of wastes. Ultimately, the objectives of these processes are: (1) to improve the efficiency of utilization of raw materials, thereby conserving resources and reducing costs; (2) to recycle waste streams within a given facility to minimize the need for effluent disposal; (3) to reduce the quantity and maximize the quality of effluent waste streams (air, water, and solids) that are created during production of goods; and (4) to transform the waste compounds into materials that may be recovered as fuels or that can be used in the production of new goods. These methods all fall under the environmental strategy represented by the widely accepted hierarchy of the 4R's: i.e, Reduce, Reuse, Recycle and Recover. There is a multitude of ways in which the transformation of process components and waste streams can be carried out. Most of these methods may be classified as being chemical and biological in nature.

Chemical transformations involve the application of reagents and reaction conditions to chemically alter species through a chain of events resulting in the yield of a desired product. Such processes involve a string of events that are usually well defined and can be controlled to maximize efficiency. However, such processes often require the presence of excess quantities of reagents to accomplish the transformation 
to the desired extent. In addition, particularly harsh conditions (e.g., high temperature or extremes of $\mathrm{pH}$ ) are often required in order to facilitate the chemical transformations. This can present a problem once the desired transformation has taken place since the resulting stream may be a low quality mixture that cannot be disposed into the environment or reused without subsequent treatment. And, finally, many chemical treatment processes are not highly selective in terms of the types of pollutants that are transformed during treatment. Consequently, such processes are usually more economical for the treatment of dilute wastewaters and are often used as a polishing step prior to waste discharge into the environment (Aitken, 1993).

Biological processes have been used with much success for many decades. These processes are designed to take advantage of the biochemical reactions that are carried out in living cells. Such processes make use of the natural metabolism of cells to accomplish the transformation or production of chemical species. The metabolic processes occur as a result of a sequence of reactions conducted inside the cell that are catalyzed by proteins called enzymes. An important advantage of biological systems is that they can be used to carry out processes for which no efficient chemical transformations have been devised. In addition, biological processes can often be conducted without the harsh conditions that are necessary during chemical transformations. However, due to the sensitivity of microorganisms to changes in their environment (e.g. $\mathrm{pH}$, salinity, temperature, and the presence of toxic or inhibitory compounds), these processes can be difficult to control over the long term, and may be subject to frequent upsets. They also require a supply of macro- and micronutrients for the support of microorganism growth, and often result in the formation of large quantities of biomass that ultimately must be discarded into the environment. In addition, the biochemical reactions occur at a rate that is limited by the metabolism of the microorganism and, thus, are often slower than chemical processes. Moreover, while biological systems are commonly used to remove the bulk organic load in wastewaters, these systems often have difficulty in removing toxic pollutants to consistently low levels. Therefore, conventional biological processes may not be able to improve water quality sufficiently to meet wastewater discharge criteria.

In an attempt to overcome some of the problems associated with chemical and biological systems, recent research has focused on the environmental applications of pure enzymes that have been isolated from their parent organisms. The reasons for this recent interest are fourfold: (1) the rate of introduction of recalcitrant organic pollutants into the environment is on the rise, and it is becoming increasingly difficult to achieve an acceptable degree of removal of these pollutants using conventional chemical and biological processes; (2) there is a need for the development of alternative treatment methods that are faster, cheaper, more reliable, and simpler to implement than current processes; (3) there is a growing recognition that enzymes can be used to target specific pollutants for treatment; and (4) recent biotechnological advances are expected to enable the production of cheaper and more readily available enzymes through genetic manipulation of microbial and plant cells and through improved efficiency of isolation and purification procedures. Much of this work remains very new and substantial hurdles must be overcome before full-scale industrial application of enzymes can become a reality. Thus, the objectives of this 
paper are: (1) to provide an introduction to enzymes, their advantages and their limitations; (2) to summarize some of the applications that have been the subject of recent research; and (3) to identify the obstacles that must be overcome before such enzymatic processes can be implemented at the full-scale.

\section{ENZYMATIC PROCESSES}

Enzymatic systems fall between the two traditional categories of chemical and biological processes, since they involve chemical reactions based on the action of biological catalysts. Specifically, enzymes are biological catalysts that regulate the multitude of chemical reactions that occur in a living cell, whether it be plant, animal or microbial. They carry out such cellular processes as energy conversion, food digestion and biosynthesis. Enzymes that have been isolated from their parent organisms are often preferred over intact organisms containing the enzyme because the isolated enzymes act with greater specificity, their activity can be better standardized, they are easier to handle and store, and enzyme concentration is not dependent on bacterial growth rates.

This can lead to some important advantages of enzymatic processes over biological systems such as: their application to compounds that resist biodegradation; their high selectivity allowing for the treatment of targeted pollutants; their action on, or in the presence of, many substances which are toxic to microbes; their operation over relatively wide temperature, $\mathrm{pH}$ and salinity ranges compared to cultures of microorganism; their operation both at high and low concentrations of contaminants; their high reaction rate compared to biological processes which enables the use of smaller systems of lower cost; the absence of shock loading effects associated with changes in contaminant concentrations that overwhelm the microorganism's ability to adapt; the absence of delays associated with shutdown/startup periods that are normally required to acclimatize biomass to waste streams; the lower quantity of sludge production since biomass is not generated; and a high system stability allowing for simpler process control.

Enzymes can also offer a number of advantages over conventional chemical processes. Such advantages include: a high degree of specificity that allows enzymes to remove target pollutants selectively, which precludes undesirable or unnecessary reactions which would otherwise increase reactant consumption and, correspondingly, increase the cost of treatment; operation on compounds that are present in trace quantities (i.e., micropollutants) or that cannot removed by existing chemical/physical processes; operation in a catalytic manner resulting in a high reaction velocity and efficient use of chemical reagents; operation under low temperature conditions, thereby reducing energy requirements for processes normally conducted at elevated temperatures; and operation under mild $\mathrm{pH}$ conditions, thereby reducing the impact of corrosion on reaction vessels and avoiding the need for waste neutralization.

While the above advantages are indeed significant, it should be noted that the majority of chemical and biological processes are not candidates for replacement by enzymatic processes. That is, biological processes and some chemical processes (e.g., oxidation) have a fundamental advantage over enzymatic systems: i.e., their ability to 
simultaneously transform a broad range of compounds. For example, many municipal, agricultural, and industrial wastes consist of a mixture of organic compounds usually classified under the broad categories of biological oxygen demand (BOD) or chemical oxygen demand (COD). Once released into receiving water bodies, these collections of organic compounds result in the depletion of dissolved oxygen in the water column as a result of natural microbial processes. In many instances, the majority of these compounds can be efficiently degraded through the combined action of mixed cultures of microorganisms. In contrast, enzymes are biological catalysts whose actions are tailored to exclusively act upon specific chemical species. Thus, enzymatic treatment will not result in the removal of a broad range of compounds from a waste stream, but will only accomplish the transformation of an individual compound or class of compounds. This limits the application of enzymes to accomplish the transformation of target species that are either problematic due to their toxicity or that have been identified as the raw materials from which enzymes can produce value-added products.

\section{POTENTIAL APPLICATIONS OF ENZYMES}

In recognition of the above, recent research has focused on the development of enzymatic processes for the treatment of wastewaters, solid wastes, hazardous wastes and soils. The environmental applications that have been discussed in the literature may be classified according to their specific objectives. For example, some processes are specifically designed to accomplish the transformation of target pollutants in wastewater streams to reduce toxicity. Alternatively, the conversion of waste materials can sometimes be achieved in a manner that results in a product with commercial value. Some applications that have been recently reported will be outlined below.

\section{Enzymatic Treatment to Improve Waste Quality}

Due to their high specificity to individual species or classes of compounds, enzymatic processes can be designed to specifically target selected compounds that are detrimental to the environment. Compounds that are candidates for this type of treatment are usually those that cannot be treated effectively or reliably using traditional techniques. Alternatively, enzymatic treatment can be used as a pretreatment step to remove one or more compounds that can interfere with subsequent downstream treatment processes. For example, if inhibitory or toxic compounds can be removed selectively, the bulk of the organic material could be treated biologically, thereby minimizing the cost of treatment. Due to the susceptibility of enzymes to inactivation by the presence of other chemicals, it is likely that enzymatic treatment will be most effective in those streams that have the highest concentration of the target contaminant and the lowest concentration of other contaminants that may tend to interfere with enzymatic treatment. Aitken (1993) suggested the following situations where the use of enzymes might be most beneficial:

- removal of specific chemicals from a complex industrial waste mixture prior to on-site or off-site biological treatment; 
- removal of specific chemicals from dilute mixtures, for which conventional mixed culture biological treatment might not be feasible;

- polishing of a treated wastewater or groundwater to meet limitations on specific pollutants or to meet whole effluent toxicity criteria;

- treatment of wastes generated infrequently or in isolated locations, including spill sites and abandoned waste disposal sites;

- treatment of low volume, high concentration wastewater at the point of generation in a manufacturing facility to permit re-use of the treated process wastewaters, to facilitate recovery of soluble products, or to remove pollutants known to cause problems downstream when mixed with other wastes from the plant.

Some potential applications of enzymes that have been identified for the improvement of waste quality include the transformation of aromatic compounds, cyanide, color-causing compounds, pesticides, surfactants and heavy metals. In addition, some physical modifications in waste characteristics have been achieved through the mixing of solid wastes with enzymes. These applications are summarized in Table 1 and are described below.

\section{(a) Aromatic Pollutants}

Aromatic compounds, including phenols and aromatic amines, constitute one of the major classes of pollutants and are heavily regulated in many countries. They are found in the wastes of a wide variety of industries including coal conversion, petroleum refining, resins and plastics, wood preservation, metal coating, dyes and other chemicals, textiles, mining and dressing, and pulp and paper. Most aromatic compounds are toxic and must be removed from wastes before they are discharged into the environment. Several methods of enzymatic treatment have been proposed as potential alternatives to conventional methods.

Peroxidase enzymes are produced in the cells of many microorganisms and plants. They catalyze a variety of reactions, but all require the presence of oxidants such as hydrogen peroxide $\left(\mathrm{H}_{2} \mathrm{O}_{2}\right)$ to activate them. Hydrogen peroxide first oxidizes the enzyme, which in turn oxidizes the substrate. The reaction products are subsequently polymerized through a non-enzymatic process leading to the formation of water insoluble precipitates that can be removed from the aqueous phase by sedimentation or filtration. Peroxidases can catalyze the oxidation of a wide variety of toxic aromatic compounds including phenols, biphenols, anilines, benzidines and related heteroaromatic compounds. Peroxidases that have been used for the laboratory-scale treatment of aqueous aromatic contaminants include horseradish peroxidase, soybean peroxidase, chloroperoxidase, manganese peroxidase, and lignin peroxidase. Of these, horseradish peroxidase (HRP) is undoubtedly one of the most studied enzymes in the relatively new area of enzymatic waste treatment. It is particularly suitable for wastewater treatment because it retains its activity over a broad range of $\mathrm{pH}$ and temperature (Nicell et al, 1993a). 
Table 1: Enzymes that can accomplish the transformation of pollutants.

\begin{tabular}{|l|l|}
\hline Enzyme & Proposed Applications \\
\hline Alcalase & Hydrolysis of tannery waste for chrome recovery \\
\hline Alkylsulfatase & Surfactant degradation \\
\hline $\begin{array}{l}\text { Chloroperoxid } \\
\text { ase }\end{array}$ & Oxidation of phenolic compounds \\
\hline Cyanidase & Cyanide decomposition \\
\hline $\begin{array}{l}\text { Cyanide } \\
\text { hydratase }\end{array}$ & Cyanide hydrolysis \\
\hline Laccase & $\begin{array}{l}\text { Removal of phenols, decolorization of Kraft bleaching } \\
\text { effluents, binding of phenols and aromatic amines with humic } \\
\text { materials }\end{array}$ \\
\hline $\begin{array}{l}\text { Lignin } \\
\text { peroxidase }\end{array}$ & $\begin{array}{l}\text { Removal of phenols and aromatic compounds, decolorization } \\
\text { of Kraft bleaching effluents }\end{array}$ \\
\hline $\begin{array}{l}\text { Lipase } \\
\text { Larbohydrase and protease) }\end{array}$ \\
\hline Lyzozyme & Improved sludge dewatering \\
\hline Mn-peroxidase & Oxidation of monoaromatic phenols and aromatic dyes \\
\hline Muramidase & Dewater of pulp and paper sludges \\
\hline $\begin{array}{l}\text { Parathion } \\
\text { hydrolase }\end{array}$ & Hydrolyzation of organophosphate pesticides \\
\hline Peroxidase & $\begin{array}{l}\text { Removal of phenols and aromatic amines, decolorization of } \\
\text { Kraft bleaching effluents, dewatering of phosphate slimes }\end{array}$ \\
\hline $\begin{array}{l}\text { Perma-Zyme } \\
\text { commercial } \\
\text { product) }\end{array}$ & $\begin{array}{l}\text { Improve the strength and stability of pure clayey soils and } \\
\text { soil-fly ash mixtures }\end{array}$ \\
\hline Phosphatase & Precipitation of heavy metals \\
\hline Proteases & Improving sludge dewatering \\
\hline Tyrosinase & Removal of phenols \\
\hline
\end{tabular}

Most research has focused on the treatment of a variety of phenolic contaminants (Klibanov, 1982; Klibanov et al, 1980). However, the use of HRP for the treatment of contaminants including anilines, hydroxyquinoline and arylamine carcinogens such as benzidines and naphthylamines has also been demonstrated in the laboratory (Klibanov et al, 1980, Klibanov and Morris, 1981). In addition, it has been shown that HRP has the ability to induce the formation of mixed polymers resulting in the removal of some compounds that are not directly acted upon by peroxidase (Klibanov et al, 1980). This phenomenon has an important practical implication for wastewaters that usually contain many different pollutants. This principle was demonstrated when it 
was observed that polychlorinated biphenyls (PCBs) could be removed from solution through co-precipitation with phenols (Klibanov, 1983). However, this particular application of HRP does not appear to have been pursued in any subsequent research. Considerable efforts have aimed at optimizing the HRP-catalyzed removal of phenols from aqueous solutions. Improvements in the useful life of the enzyme, and thereby a reduction in treatment cost, have been accomplished through: selection of an appropriate reactor configuration (Nicell et al, 1993b); the use of additives such as polyethylene glycol to protect the enzyme from premature inactivation (Nakamoto and Machida, 1992); the addition of absorbents such as talc which protect the enzyme from inhibition by reaction products (Arseguel and Baboulène, 1994); and the immobilization of the enzyme on solid supports (Bodzek et al, 1994). In particular, the advantages of immobilization for enzymes can include the preservation of enzyme activity (Coppella et al, 1990), the potential for continuous flow treatment (Caldwell and Raushel, 1991) and the possibility of enzyme reuse (Munnecke, 1977). Thus, this methodology has been pursued during the development of many different types of enzymatic processes, as will be seen below.

Lignin peroxidase (LiP), also known as ligninase, was first reported in 1983 (Aitken et al, 1994). It is produced by the white-rot fungus Phanerochaete chrysosporium (Aitken and Irvine, 1989; Venkatadri and Irvine, 1993). In contrast to other peroxidases, LiP was shown to be capable of mineralizing a variety of recalcitrant aromatic compounds (i.e., breaking them down into smaller molecules rather than achieving their polymerization) and to oxidize a number of polycyclic aromatic and phenolic compounds (Aitken et al, 1994). LiP's role in breaking down lignin has also been confirmed (Hammel, 1989; Cornwell et al, 1990). Cornwell et al (1990) reported that immobilization of $\mathrm{LiP}$ on porous ceramic supports did not adversely affect LiP's stability and showed a good potential for degradation of environmentally persistent aromatics. Immobilization can greatly enhance the feasibility of the process because the enzyme is retained in the reactor system and does not have to be supplied continuously to the wastewater stream.

The Kraft process that is widely used in wood pulping leaves behind 5 to $8 \%$ by weight of residual modified lignin in the pulp. This residual is responsible for the characteristic brown color of the pulp and is commercially removed by the use of bleaching agents such as chlorine and chlorine oxides (Kirk and Yang, 1979). Bleaching operations produce dark-brown colored effluents that contain toxic and mutagenic chlorinated products that constitute an environmental hazard (Royer et al, 1991). A number of studies have focused on the use of microorganisms in the treatment of bleaching effluents and lately there has been an interest in the potential use of enzymes such as peroxidases and laccase to perform the same task. Ferrer et al (1991) reported the use of horseradish peroxidase and lignin peroxidase (LiP) in the color removal of Kraft mill effluents. Both enzymes were found to have considerable potential and it was also observed that the immobilized form of the enzymes was in all cases more efficient than the free form. LiP from P. chrysosporium was also found to play a positive role in color removal of bleaching effluents and it was explained that LiP was thought to degrade lignin by catalyzing the oxidation of aromatic units to cation radicals that can spontaneously decompose (Pellinen et al, 1988). 
Other peroxidases from fungal sources have also been investigated. A fungal peroxidase from Coprinus macrorhizus was used by Al-Kassim et al (1994) to treat aqueous phenols in batch reactors. Chloroperoxidase from the fungus Caldariomyces fumago has been reported to oxidize several phenolic compounds. In addition, it has been shown to catalyze certain oxygen transfer reactions such as the oxidation of ethanol to acetaldehyde or the oxidation of chloride ions. This latter reaction might lead to the formation of a different range of products (which may be more toxic) when chloride ions are added to reaction mixtures containing chloroperoxidase (Aitken et al, 1994). Manganese peroxidase, produced by Phanerochaete chrysosporium has also been observed to catalyze the oxidation of several phenols, and aromatic dyes, but these reactions depend on the presence of both manganese and certain types of buffers (Aitken and Irvine, 1989). Unfortunately, the enzyme's requirement for high concentrations of manganese makes its feasibility for wastewater treatment applications doubtful (Aitken et al, 1994).

Polyphenol oxidases represent another family of enzymes that have also been shown to catalyze oxidation reactions of phenolic compounds. They are subdivided into two subclasses: tyrosinases and laccases. In contrast to peroxidase enzymes that require the presence of hydrogen peroxide to accomplish the transformation of aromatic pollutants, both of these enzymes use oxygen to carry out their reactions (Bollag, 1992). This represents an important advantage over peroxidases due to the difficulty in safely transporting and handling hydrogen peroxide, and the ready availability and low cost of oxygen.

Tyrosinase catalyzes reactions with phenols resulting in the formation of $o$ quinones. Quinones are mostly unstable and undergo non-enzymatic polymerization to yield substances of low solubility (Atlow et al, 1984; Wada et al, 1993; Sun et al, 1992). Since a precipitate did not form spontaneously as in the case of peroxidases, Wada et al (1993) resorted to the use of chitin and chitosan to adsorb the reaction products formed. Chitin is an abundant and cheap polysaccharide available as shellfish waste, while chitosan is a product derived from chitin. Although chitosan was better at removing the colored reaction products than chitin, both adsorbed the products quickly. One advantage to using such an approach is the conversion of a waste product from the shellfish industry to a useful product. However, if chitosan is to be stripped of adsorbed material and reused, the cost of such an operation might be high in view of the strong adsorption of quinones to chitosan (Sun et al, 1992). Ikehata and Nicell (2000) reported that the use of chitosan in combination with tyrosinase accomplished very good detoxification of solutions of aqueous phenols. Wada et al (1993) also used immobilized tyrosinase along with chitosan to treat phenols and observed $100 \%$ phenol removal within two hours. The immobilization of tyrosinase has the advantage of retaining enzymes in the reactor and protecting them from inactivation by reaction with quinones (Wada et al, 1992; 1993). It should be noted, however, that despite the savings associated with using oxygen as an oxidant, the cost of mushroom tyrosinase is currently very high.

Laccase is produced by several fungi and seems capable of decreasing the toxicity of phenolic compounds through a polymerization process (Bollag et al, 1988). Also, because of its relative non-specificity, it can induce the cross-coupling of pollutant 
phenols with naturally occurring phenols. In fact, laccase can oxidize phenolic compounds to their corresponding anionic free radicals that are highly reactive (Bollag, 1992). In a study performed on laccase from the fungus Rhizoctonia praticola, Bollag et al (1988) demonstrated the ability of the enzyme to detoxify some of the phenolic compounds tested. Detoxification of a particular phenol appeared to be dependent on the ability of the enzyme to transform the compound, as demonstrated by the disappearance of the parent phenol. However, the reaction products were not identified. Bollag et al (1988) concluded that the ability of laccase to detoxify a solution containing phenols appears to be function of the compound being treated, the source of the enzyme and other environmental factors. Laccase has also been cited as a possible candidate for the treatment of bleaching plant effluent (Milstein et al, 1988; Lankinen et al, 1991). In a study on the removal of chlorophenols and chlorolignins from bleaching effluents by precipitation, Milstein et al (1988) reported that laccase could polymerize low-molecular-mass phenols, thereby facilitating their removal by reaction and precipitation with polyethyleneimine. Royer et al (1991) noted that intracellular enzymes (not identified) of the fungus Coriolus versicolor had some effect on effluent decolorization. Whereas enzymes in their free form caused some decolorization, immobilized enzymes had a more pronounced result.

Bollag (1992) suggested that it is possible to enhance the natural process of the binding and incorporation of xenobiotics into humus by adding enzymes such as laccase to contaminated soils. Laccases from Trametes versicolor, Rhizoctonia praticola and other fungi have been used to enhance the binding through oxidative coupling of various chlorinated phenols and aromatic amines with phenolic humic constituents. The advantages of such a process would be to immobilize and detoxify hazardous compounds. Binding of pollutants to humic material would decrease the amount of pollutant available to interact with the flora and fauna, reduce the toxicity of the pollutants through the coupling process, and prevent chemicals leaching through the formation of insoluble precipitates. The xenobiotics seem to be stable once incorporated into the soil. They are released minimally and gradually, which should not constitute any health hazard, and the released compounds can be mineralized or bound again to humus by natural processes.

\section{(b) Pesticide Residues}

Pesticides, which include herbicides, insecticides and fungicides, are widely used throughout the world today for crop protection and it is expected that this use will continue to grow (Smith et al, 1982). The potential adverse effects that the pesticide industry can have on the environment arise from the disposal of wastes formed during production and formulation of pesticides, detoxification of pesticide containers and spray tanks and the pollution of surface and groundwater by pesticide runoff (Munnecke, 1977; 1978). Common treatment methods include incineration, chemical methods and landfilling. However, these systems have serious limitations including high cost, production of hazardous byproducts, disposal of chemical reagents, and the susceptibility of sensitive biological treatment systems to sudden changes in contaminant concentrations (Caldwell and Raushel, 1991). 
It has been proposed that parathion hydrolase enzyme be used for pesticide detoxification as an alternative to more common treatment methods. Parathion hydrolase is produced by a number of bacteria including Pseudomonas sp., Flavobacterium sp. and a recombinant Streptomyces (Smith et al, 1982; Coppella et al, 1990). It has been shown to hydrolyze a number of the most widely used organophosphate pesticides such as methyl and ethyl parathion, diazinon, fensulfothion, dursban and coumaphos (Munnecke, 1977; Caldwell and Raushel, 1991). It should be noted that organophosphate pesticides constitute the major proportion of agricultural pesticides used at present and are implicated in an estimated 800000 pesticide poisoning cases every year (Caldwell and Raushel, 1991). Several researchers have studied the hydrolysis of the insecticide "coumaphos" by parathion hydrolase. Coumaphos is used to kill a cattle disease-causing tick by dipping the cattle in large vats of the pesticide. When anaerobic dechlorination of coumaphos occurs (as is the case in the dip vats used), a product called potasan is formed. Since potasan is toxic to cattle, the contents of the vats used for cattle dipping have to be renewed frequently thus generating a large volume of coumaphos-based waste (Smith et al, 1982). The hydrolysis products of coumaphos and potasan are chlorferon and 4methylumbelliferon, respectively (Smith et al, 1982). These hydrolysis products are much more soluble than the initial substrates and can be treated using ultraviolet light in combination with ozonation. Parathion hydrolase has been shown to successfully hydrolyze coumaphos much more rapidly than chemical hydrolysis and it was further shown to selectively hydrolyze potasan while preserving coumaphos, when specific amounts of enzymes were involved (Coppella et al, 1990). The advantage of this latter process is the prolongation of coumaphos' useful life and the resulting decrease in coumaphos waste generation. In laboratory experiments, free parathion hydrolase was stable at temperatures up to $45-50^{\circ} \mathrm{C}$, and over the $\mathrm{pH}$ range 5.5 to 10.0 . Munnecke (1977) reported the successful hydrolysis of organophosphate insecticides with parathion hydrolase immobilized on glass.

\section{(c) Cyanide Wastes}

It is estimated that 3 million tons of cyanide are used yearly throughout the world in different industrial processes including the production of chemical intermediates, synthetic fibers, rubber and pharmaceuticals, as well as in ore leaching, coal processing and metal plating (Basheer et al, 1992). Also, many plants, microbes and insects can release hydrogen cyanide from the enzymatic hydrolysis of certain compounds they produce (Basheer et al, 1993). Finally, effluents of food and feed production also contain substantial amounts of cyanide whose source is the cyanogenic glycosides of various crop materials (Basheer et al, 1992). Since cyanide is a metabolic inhibitor and can be lethal to humans and other organisms, it is essential that it be removed from effluents prior to discharge (Basheer et al, 1992; 1993).

Cyanidase is an enzyme preparation capable of converting cyanide in industrial wastewaters to ammonia and formate in what appears to be a single-step reaction (Basheer et al, 1993). Cyanidase is based on certain gram-negative bacterial isolates from the genus Alcaligenes denitrificans and it is prepared by proprietary methods. It 
is characterized by a high affinity and a high stability toward cyanide and is able to remove the latter down to very low levels, i.e. $<0.02 \mathrm{mg} / \mathrm{L} \mathrm{CN}^{-}$(Basheer et al, 1992). Cyanidase activity was neither affected by the common ions normally present in wastewaters (e.g., $\mathrm{Fe}^{2+}, \mathrm{Zn}^{2+}$ and $\mathrm{Ni}^{2+}$ ), nor by organic substrates such as acetate, formamide, acetamide and acetonitrile. In a study done on the detoxification by cyanidase of a cyanide-containing extract from debittering apricot seeds in the food industry, Basheer et al (1993) developed a diffusional-type flat membrane reactor (FMR) and noted its superior performance relative to stirred tank reactor and fixed bed reactor configurations. The advantages of an FMR include the protection of the enzyme from interfering particles and large molecules to avoid attrition and shear damage to the immobilization support. Cyanide diffuses through a semi-permeable membrane to react with the entrapped enzyme behind the membrane and reaction products diffuse back across the membrane to the solution.

Cyanide hydratase, also known as formamide hydrolyase, has been reported to hydrolyze cyanide to formamide (Basheer et al, 1993; Nazly et al, 1983). Cyanide hydratase is produced by a variety of fungi and is inducible upon pre-exposure of the fungi to low concentrations of cyanide. Nazly et al (1983) noted that cyanide hydratase was more stable when immobilized and that the enzyme from Gloeocercospora sorghi was much more stable than that from Stemphylium loti. They concluded that immobilized fungal cyanide hydratase is suited for the treatment of industrial effluents containing cyanide.

\section{(d) Heavy Metals}

Heavy metals such as arsenic, copper, cadmium, lead and chromium, among others, are hazardous contaminants found in a number of industrial and mining waste streams as well as in solid wastes, municipal sewage sludges and landfill leachate (Pradham and Levine, 1992). Cadmium, for instance, is present in wastes from the mixing, smelting, electroplating and pigment manufacture while other metals are used in the nuclear power, defense and fuel reprocessing industries (Macaskie and Dean, 1984; Macaskie et al, 1987). In view of the high toxicity of these heavy metals, they must be prevented from being discharged into receiving water bodies. Macaskie and Dean (1984) reported the use of a technique to remove heavy metals from liquid electroplating and other industrial wastes. They claimed that removal of cadmium, lead, copper, uranium and strontium was thus successfully achieved. The process involves the use of Citrobacter sp. cells immobilized in polyacrylamide gel, through which metal-containing solutions are passed. A cell-bound phosphatase enzyme, induced during pre-growth by providing the substrate glycerol 2-phosphate as a sole phosphorus source, liberates inorganic phosphate in excess of that needed for growth. The latter, in turn, combines with the metal to form an insoluble metal phosphate at the cell surface. It was reported that more than $90 \%$ metal removal was observed and that the metal could be recovered from the immobilized cells that could be reused (Macaskie et al, 1987). The optimal temperature for the cells was found to be $30^{\circ} \mathrm{C}$ while phosphatase was relatively stable over the $\mathrm{pH}$ range 5 to 9 . Although phosphatase was largely unaffected by the presence of high amounts of chloride $\left(\mathrm{Cl}^{-}\right)$, 
cyanide $\left(\mathrm{CN}^{-}\right)$concentrations in excess of $5 \mathrm{mM}$ severely hampered cadmium accumulation by the cells. These species are often found in electroplating wastes. It was suggested that polyacrylamide gel was not suited for full-scale applications as an immobilizing agent, and that glass and other inert supports seemed to offer better alternatives (Macaskie et al, 1987). Kimura et al (1999) demonstrated the use of an enzyme called Alcalase to treat and recover the chromium from chrome shavings that are an important waste of tannery industries. The treatment reduced the chromium concentration in the wastes from a starting concentration of $26.6 \mathrm{~g} / \mathrm{Kg}$ to a final concentration of $4 \mathrm{mg} / \mathrm{Kg}$.

\section{(e) Solid Wastes}

Enzymes have also been used to improve the dewatering of sludges that are produced as a by-product of wastewater treatment. Dewatering is essential to reduce the mass of water contained in sludges that are to be incinerated or discarded into landfills. Thomas et al (1993) used an enzyme product containing carbohydrase, lipase and protease activities to improve the dewaterability of sewage sludge and to increase the quantity of water released during pressing in order to achieve a reduction in sludge volume. The effect of enzyme addition was to cause the cleavage of the water-binding macromolecules. However, whereas an enzyme dose of 2.5 to $5 \mathrm{mg} / \mathrm{L}$ gave good results, an increased dose led to the creation of more hydrophilic end groups that negatively affected the dewatering process. Attempts to dewater phosphate slimes were reported by Anazia and Misra (1989). Phosphatic slimes contain considerable amounts of swelling clay-like material and their fine particle size, along with their slow settling behavior, makes them particularly difficult to dewater. Anazia and Misra (1989) proposed the use of peroxidase to improve the dewatering of these slimes. They reported that peroxidase pretreatment of the slimes induced a higher mechanical binding among slime particles and that peroxidase significantly promoted the growth of algae and mold with the beneficial effect of enhanced aggregation of the particles and very high viscosity and gel strength. Such high viscosity and gel strength would help in post-sedimentation handling. Hakulinen (1988) reported on the use of cellulase and the bacterial enzyme lyzozyme, or muramidase, for sludge dewatering. While cellulase was used with penicillin and gave rather poor results, lyzozyme was allegedly able to alter floc matrices and to cause a dramatic increase in dewatering rates.

Khan and Sarker (1993) experimented with the effect of enzyme addition on the strength and stability of pure clayey soil and soil-fly ash mixtures. The results obtained were encouraging. The addition of enzyme to a fly-ash-kaolinite soil mixture (5\% fly ash) continuously increased the strength of the mixture and at $10 \%$ enzyme concentration (when enzyme addition was stopped) the unconfined compressive strength of the mixture had increased by about $53 \%$. The advantages of using enzymes in soil-fly ash stabilization is to help avoid the necessity for the disposal of fly ashes while at the same time increasing the strength of the soil. Fly ash constitutes around $90 \%$ of coal-combustion residues and it is estimated that around 65 million tons are produced yearly in the United States alone. In this context, enzymatic stabilization of fly ash compares well to other stabilization processes and may actually be cheaper 
(Khan and Sarker, 1993). The enzyme that was used was a commercial enzyme product known as "Perma-Zyme". The authors mentioned that it was a product of fermentation and that it had no corrosive or toxic effects but they did not identify the specific enzyme activities it contained.

\section{(f) Surfactants}

Surfactants or "surface active" agents are organic substances that have rather large polar molecules and are basic ingredients of detergents. Surfactants may cause significant pollution problems when high concentrations from shampoo formulation factories, for instance, enter municipal sewerage systems and generate undesirable conditions such as foaming (Thomas and White, 1991). Thomas and White (1991) reported that immobilized alkylsulfatase from Pseudomonas C12B could efficiently degrade surfactants up to a concentration of $750 \mathrm{mg} / \mathrm{L}$. The enzyme, which was observed to be specific to primary alkyl sulfates, was able to completely degrade alkyl sulfate and alkyl ethoxy sulfate surfactants in pure and commercial forms and had some effect on aryl sulfonates. However, the enzyme was practically incapable of attacking alkane sulfonates. Overall, alkylsulfatase showed promise for future use in the treatment of a range of surfactants found in shampoo formulation waste streams.

\section{Enzymatic Treatment for the Production of Value-added Materials}

Waste treatment processes can be a significant financial burden to those companies or communities who operate them. Therefore, growing emphasis is being placed on the development of waste valorization strategies based on the recognition that waste products can be used as a source of raw materials for the production of goods. Such strategies have some important advantages. First, by replacing conventional sources of raw materials with a waste source, resources are conserved. Secondly, the conversion of wastes results in a decrease in the quantity of materials that must be discarded. And, thirdly, this strategy can be used to produce new materials that can be a source of profit or can be used to offset waste treatment costs. Recent research has shown how enzymes can fit into a waste valorization strategy by chemically converting target components of various waste matrices into food products, sugars, ethanol, commodity chemicals, or degradable plastics. These types of applications are summarized in Table 2 and are discussed below.

\section{(a) Food Processing Wastes}

The food processing industry produces extremely large quantities of wastes. However, whereas the wastes generated by other industries are generally deleterious and must be rendered innocuous by appropriate treatment schemes, food wastes have the advantage of being amenable to conversion into food, feed or non-food products with added value. Recently, the potential for using enzymes in food waste handling has been suggested (Blasheck, 1992). Enzymes could be used to decrease food wastes via enzymatic processing to yield higher-value by-products (Shoemaker, 1986). 
Table 2: Enzymes that can convert wastes to value-added products.

\begin{tabular}{|l|l|}
\hline Enzyme & Proposed Applications \\
\hline $\begin{array}{l}\text { Amylases: á-amylase, } \\
\text { glucoamylase }\end{array}$ & $\begin{array}{l}\text { Starch hydrolysis to produce glucose, lactic acid } \\
\text { and biodegradable plastics }\end{array}$ \\
\hline $\begin{array}{l}\text { Cellulolytic enzymes: } \\
\text { cellulase, cellobio-hydrolase, } \\
\text { cellobiase, exo-1,4-â-D- } \\
\text { glucosidase }\end{array}$ & $\begin{array}{l}\text { Hydrolysis of cellulosic materials from pulp and } \\
\text { paper and municipal solid wastes to produce } \\
\text { sugars and alcohol }\end{array}$ \\
\hline Chitinase & $\begin{array}{l}\text { Bioconversion of shellfish waste to N-acetyl } \\
\text { glucosamine }\end{array}$ \\
\hline L-galactono-lactone oxidase & $\begin{array}{l}\text { Conversion of galactose from whey hydrolysis to } \\
\text { L-ascorbic acid }\end{array}$ \\
\hline Pectinesteras, pectine lyase & Degradation of pectin to produce butanol \\
\hline Lactases & $\begin{array}{l}\text { Dairy waste processing and production of value- } \\
\text { added products }\end{array}$ \\
\hline Proteases & Solubilization of fish and meat remains \\
\hline
\end{tabular}

Proteases are a group of hydrolases that are widely used in the food industry in processing fish and meat waste. Proteases can solubilize proteins in waste streams, resulting in recoverable liquid concentrates or dry solids of nutritional value for fish or livestock (Shoemaker, 1986). Dalev (1994) reported the use of alkaline protease from Bacillus subtilis in the processing of waste feathers from poultry slaughterhouses. Feathers constitute 5\% of the body weight of poultry and can be considered as a high protein source for food and feed provided their rigid keratin structure is completely destroyed. Total solubilization of the feathers was achieved after pretreatment with sodium hydroxide, mechanical disintegration and enzyme hydrolysis. The end product was a heavy, grayish powder with a very high protein content that could be used mainly as feed constituent. Venugopal et al (1989) immobilized cells from Bacillus megaterium, Pseudomonas marinoglutinosa and Acromonas hydrophila in calcium alginate. The proteases secreted by these cells were used to solubilize fish meat.

Amylases are polysaccharide hydrolases that have been used in the simultaneous saccharification and fermentation of starch (Blashek, 1992) and the treatment of starch-containing food wastewaters (Shoemaker, 1986). Shoemaker (1986) reported that amylases could be used to produce alcohol from rice processing wastewater. It was also reported that amylases seemed to enhance activated sludge wastewater treatment by reducing the treatment time. Coleman (1990) reported a very interesting application of á-amylase and glucoamylase enzymes in the production of photodegradable and biodegradable plastics. The process used involves the conversion of the starchy material contained in cheese whey or potato waste from commercial food processing to truly biodegradable plastics. á-Amylase is firstly used to break 
down the long starch molecule into smaller fragments. The latter are then attacked by glucoamylase to produce glucose through saccharification. During this process more than $90 \%$ of the starch is converted to glucose. The glucose is then fermented to lactic acid that is recovered, purified and used in the production of photo- and biodegradable plastics whose rate of decay can be controlled by judicious mixing of various lactic acid isomers and other compounds. The end product is 95\% lactic acid and 5\% of an environmentally safe product. Besides reducing starchy food wastes and producing a valuable product, photo- and biodegradable plastics can be used in the preparation of mulch films and compost bags and can also be used as programmable fertilizer and pesticide delivery systems thus offering a possible solution to pesticide runoff that result from the excessive quantities applied (Coleman, 1990).

Pectinesterase from Clostridium thermosulfurogenes and pectin lyase from Clostridium beijerinckii has been reported to degrade pectin, which is a water-soluble substance that binds adjacent cell walls in plants. It has been shown that apple pomace (a food processing waste) can be degraded using pectinesterase to yield butanol (Blasheck, 1992). The enzyme L-galactonolactone oxidase, from the yeast Candida norvegensis can be used to bioconvert galactose resulting from the hydrolysis of the lactose contained in whey to L-ascorbic acid which is a valuable commodity chemical (Shoemaker, 1986). Lactases have also been used in dairy wastes' processing, mainly to produce value-added products (Blasheck, 1992; Shoemaker, 1986). Whey protein concentrate can be separated from permeate solids which contain high levels of lactose whose degradation and transformation is sought through enzymatic action (Blasheck, 1992). Billions of kilograms of whey are produced yearly (Blasheck, 1992) and therefore any beneficial treatment of whey could have a significant positive impact on the environment. Chitinase from Serratia marcescens QMB1466 has also been cited for its ability to induce chitin degradation. In fact, the bioconversion of chitin to yeast single-cell protein has been proposed as an alternative to the disposal of shellfish wastes that have high chitin contents (Cosio et al, 1982). The process consists of pretreating shrimp waste by size reduction, deproteination and demineralization to produce a chitin material that can be converted by chitinase to the monomer $\mathrm{N}$-acetyl glucosamine. The latter serves as a substrate for the single-cell protein production.

Bajza and Markovic (1999) used an unspecified enzyme to treat leather wastes. The degradation of leather wastes yielded a water-soluble hydrolysate that could be concentrated and dried to produce fine-grained flour that they claimed can be used for a variety of commercial purposes.

\section{(b) Solid Wastes}

For the past decade, there has been an increasing interest in the enzymatic hydrolysis of cellulose, a major component of paper (Clanet et al, 1988). This interest stems from the advantages that such a process would offer; namely, the conversion of lignocellulosic and cellulosic wastes to a useful energy source through the production of sugars, ethanol, biogas or other energetic end products (Coughlan, 1992; Lagerkvist and Chen, 1993). However, the industrial production of sugars from cellulose has been plagued with a number of constraints pertaining to enzyme production and cost and 
substrate preparation, among others. Still, there have been numerous reports on the possible ways of improving the hydrolysis of the cellulose contained in the organic fraction of municipal solid wastes (MSW) in order to produce sugars and eventually ethanol or butanol. Clanet et al (1988) have used cellulases from Trichoderma reesei CL847, penicillium strain CLD20 and the thermophilic fungus CL240 to obtain hydrolysates from the organic fraction of MSW that would be directly used as base for fermentation media. Sugar concentrations as high as $45 \mathrm{~g} / \mathrm{L}$ were produced in a packed-column reactor and the hydrolysates obtained could reportedly be used in anaerobic fermentations such as acetone-butanol or organic acid production.

Rivers and Emert (1988) studied the effects of a number of parameters on the yields of enzymatic hydrolysis for two major MSW components; namely, newspaper and corrugated cardboard. Their primary aim was to try to determine the modifications of MSW that would lead to increased conversions to ethanol. A full complement cellulase system from Trichoderma reesei $\mathrm{QM} 9414 \mathrm{G}$ was used. The enzyme system consisted of endoglucanase, cellobiohydrolase and cellobiase. Another study involving the fungal enzyme preparation "Econase" was conducted to investigate the effect of cellulolytic enzymes on MSW degradation (Lagerkvist and Chen, 1993). Econase consists mainly of endo-1,4-â-D-glucanase, cellobiohydrolase and exo-1,4-â-Dglucosidase in addition to a number of other enzymes. The use of Econase seemed to enhance the degradation of MSW as well as cellulose degradation.

There have also been some reports on the use of cellulolytic enzymes in the treatment of sludges from pulping and deinking operations. Duff et al (1994) performed studies investigating the possibility of hydrolyzing the highly cellulosic sludges that result from pulp and paper operations to produce an energy source such as ethanol. Since an average of $60 \mathrm{~kg}$ of primary sludge are generated per tonne of pulp produced, ethanol production is evidently an attractive way of decreasing the amount of sludges that have to be handled and disposed while producing a marketable product. The enzymes used included a blend of cellobiohydrolase, cellulase and â-glucosidase. In another study, Duff et al (1995) focused on the conversion of low-value cellulosic substrates from fiber recycling and deinking operations to fermentable sugars. The enzymes used were not inhibited by high ink content and it was observed that the presence of surfactants enhanced the rate of enzymatic hydrolysis especially in the early stages of the reaction.

\section{DISCUSSION}

Enzymes have undoubtedly stimulated the scientific community's interest and have been investigated for their potential use in many types of applications. Applications have been demonstrated that (1) aid in the efficient use of raw materials, (2) improve the quality and reduce the quantities of wastes for disposal, and (3) catalyze the transformation of waste compounds into value-added products. Other applications, not discussed here, include the use of enzymes to replace processes that have significant environmental impacts. For example, paper manufacturers have investigated the use of enzymes as means of reducing energy consumption during deinking operations (Brenner, 1998). Alternatively, in an approach that has already 
been adopted by industry, enzymes such as xylanase have been used to reduce or replace the use of chlorine in bleaching systems (Brenner,1998). In a similar manner, enzymes are now used in many household detergents. Also, Grasshoff (1999) reported the use of enzymatic cleaning solutions for the cleaning of milk heaters in Germany. It was estimated that this could eliminate the need for the disposal of approximately 1000 tons of non-biodegradable cleaning chemicals per year. All these approaches demonstrate the application of enzymes as a means of pollution prevention.

However, despite the number of proposed applications of enzymes, few of them have been developed sufficiently for full-scale application due to some very important issues that remain to be resolved. For example, Aitken (1993) pointed out some important criteria that must be met before an enzyme can be considered for any particular waste treatment application. These criteria included the following: (1) the reaction products must be less toxic, more biodegradable or more amenable to subsequent treatment than the targeted pollutant; (2) the ability of the enzyme to selectively act upon the target pollutant must be confirmed; (3) the enzyme must exhibit a reasonable amount of catalytic activity under typical treatment conditions; (4) the reactor systems that are used to implement enzymatic reactions must be relatively simple in order to be accepted by potential users of the technology; (5) the enzyme must be relatively stable under the required reaction conditions; and (6) the enzymes must be available commercially. These criteria represent major barriers to the development of enzymatic systems. Some of the most significant hurdles that must be addressed before the full potential of enzymes may be realized are discussed below.

\section{Enzyme Cost}

While many authors have recognized the potential for enzymatic treatment systems, the development of these processes from an engineering perspective is conspicuously lacking. The primary reason for this appears to be the cost of enzymes that have traditionally been very expensive to produce in the quantities that are required at an industrial scale. Enzymes are expensive because of the cost of their isolation, purification and production. Some recent research has focused on improving the economics of enzymatic systems through the direct use of plants or plant materials that contain enzymes, the use of crude enzyme extracts, the development of cloned cells that can be stimulated to produce enzymes efficiently in reactor systems, and transgenic manipulation of plants to stimulate enzyme production. Specific examples of some of these efforts are described below.

Dec and Bollag (1994) reported the successful use of plant material to decontaminate water polluted with phenolic compounds through enzymatic reactions. Peroxidases from minced horseradish, potato and white radish were used to remove 2,4-dichlorophenol up to concentrations of $850 \mathrm{mg} / \mathrm{L}$ and the removal rates achieved were comparable to those of purified HRP. Cooper and Nicell (1996) successfully used a crude extract of juice from horseradish roots to treat a foundry waste. The degree and efficiency of treatment were similar when comparing the performance of the crude extract and a purified stock of HRP. A number of other plants such as potatoes, cauliflower, cherries, soybeans and several fungi may also be used as sources 
of peroxidase enzymes. Soybeans, in particular, may represent a valuable source of peroxidase since the enzyme is found in the seed coat, which is a waste product from soybean-based industries (Wright and Nicell, 1999). In this case, it may be possible to use the solid waste from the soybean industry to treat the wastewaters of various chemical industries. In fact, the direct use of raw soybean hulls to accomplish the removal of phenol and 2-chlorophenol has been demonstrated (Flock et al, 1999). However, it should be noted that this type of approach would result in an increase in the amount of solid residues that must be disposed following treatment. Adler et al (1994) used peroxidases extracted from tomato and waterhyacinth plants to polymerize phenolic substrates. They also used the actual plant roots for in vivo experiments of pollutant removal. The peroxidases studied accomplished good removal of the test substrate guaiacol and the plant roots precipitated the phenolic pollutants at the roots' surface. The authors suggested the use of plant roots as natural immobilized enzyme systems to remove phenolic compounds from aquatic systems and soils. The direct use of plant material as an enzyme source represents a very interesting alternative to the use of purified enzymes due to its potentially lower cost. However, further studies are needed to confirm the feasibility of such a process.

Genetic engineering techniques are also expected to play a significant role in enzyme production. Taya et al (1989) reported the successful development of a hairy root clone from horseradishes and the development of cultures in a bioreactor. These cultures had peroxidase activity comparable to that of the original plant. This development of a peroxidase production system independent of field-grown horseradish is extremely advantageous in terms of the commercial production of peroxidase. Very recently, the development of molecular farming techniques has dramatically improved the potential for application of these enzymes at the industrial scale. For example, new techniques that involve transgenic manipulation of plants have opened up the possibility of using plants as factories for the production of enzymes in bulk quantities. Transgenic techniques involve the genetic engineering of plant material aimed at improving the productivity of the crop and to increase the levels of natural or foreign enzymes in the plant cells. In comparison to typical fermentation techniques, plants offer lower unit production costs, a better safety profile, shorter development time, simpler commercial scale-up, relative genetic stability, convenient storage, and potentially easier purification. For products where large volumes are wanted but a high degree of purification is not required (such as in waste treatment operations), plants appear to offer a clear advantage. It is expected that the use of transgenic plants could reduce the price of bulk enzyme production by as much as 2 to 4 orders of magnitude below that of current techniques based on animal cell culture and microbial fermentation technologies (Davies, 1998). Tobacco has recently been identified as a very suitable plant that can be manipulated to produce rich sources of industrial enzymes (Worley, 1998). For example, peanut (Arachis hypogaea) peroxidase was expressed in transgenic tobacco plants and represented about $0.3 \%$ of the total soluble proteins (Lige et al, 1998). In addition, peroxidases derived from sweet potatoes were expressed in high levels in tobacco (Huh et al, 1998). Young fully expanded leaves of transgenic plants showed higher peroxidase activity than those of non-transgenic plants. Several different enzymes have already 
been produced in the tobacco and, as such, researchers are launching into an extensive program to develop this alternate use of tobacco (Davies, 1998). This could have profound implications for tobacco farmers who have been experiencing a decline in income. Other plants can also be manipulated to produce enzymes. These developments foreshadow the production inexpensive sources of enzymes.

The current high cost of enzymes should by no means hamper the efforts to carry out more extensive research to identify the most promising enzymes and determine the optimal conditions for their use. In fact, the results of such research would provide the incentive for commercial development to eventually achieve large-scale production of the enzymes at a much lower cost.

\section{Effectiveness Under Waste Treatment Conditions}

Numerous studies have shown that the enzymatic process can be used for the treatment of synthetic wastewaters consisting of aromatic compounds dissolved in aqueous solutions. However, the composition of real wastewaters vary a great deal in terms of aromatic pollutant concentrations, suspended solids, oil and grease, $\mathrm{pH}$, bulk organic concentration (BOD, COD), and concentrations of specific chemicals that may interfere in the polymerization process. Despite this, little information has been collected with respect to the performance of enzymes under actual waste conditions.

In the case of peroxidases, brief studies by Klibanov (1983) demonstrated that industrial effluents including coal-gasification wastewater $(2000 \mathrm{mg} / \mathrm{L}$ phenol, $\mathrm{pH}$ 9.0), flushing liquor from a coke plant $(400 \mathrm{mg} / \mathrm{L}$ phenol, $\mathrm{pH}$ 8.6) and effluent from a triarylphosphate plant $(100 \mathrm{mg} / \mathrm{L}$ total phenols, $\mathrm{pH} 7.8)$ could be treated successfully. Schmidt and Joyce (1981) used horseradish peroxidase and $\mathrm{H}_{2} \mathrm{O}_{2}$ to increase removal of low molecular mass color bodies (lignin fragments and derivatives) from biologically treated pulp mill effluents by $50 \%$ above that achieved using lime precipitation alone. Treatment conditions were not optimized in the above studies and, consequently, the amount of enzyme required was excessive. Foundry wastewater $(330 \mathrm{mg} / \mathrm{L}$ total phenols, $\mathrm{pH} 6.5)$ was successfully treated resulting in more than 99\% removal of total phenols (Cooper and Nicell, 1996). Enzyme requirements were significantly reduced through optimization of treatment conditions and the use of polyethylene glycol as an additive. The phenol content of petroleum refinery wastewater ( $45 \mathrm{mg} / \mathrm{L}$ total phenols, $\mathrm{pH} 8.6,300 \mathrm{mg} / \mathrm{L} \mathrm{COD}, 90 \mathrm{mg} / \mathrm{L}$ BOD, $17 \mathrm{mg} / \mathrm{L}$ suspended solids) was reduced below the discharge limit following treatment with HRP (Wagner and Nicell, 2001). Approximately $58 \%$ of COD, $78 \%$ of $\mathrm{BOD}_{5}$, and $95 \%$ of toxicity were removed along with the phenols. During treatment, phenols were transformed into less-biodegradable compounds that could be removed by coagulation. Optimization of the peroxide dose led to 20\% enzyme savings. The use of polyethylene glycol and chitosan as protective additives resulted in 4- and 25-fold reductions in enzyme requirements, respectively. Phenol removal did not appear to be affected adversely by the presence of hydrocarbons that are frequently present in refinery wastewaters. Wagner and Nicell (2000) treated a foul condensate from a Kraft mill ( $15 \mathrm{mg} / \mathrm{L}$ total phenols, pH 9.4, $1600 \mathrm{mg} / \mathrm{L} \mathrm{COD,} 200 \mathrm{mg} / \mathrm{L}$ suspended solids) with HRP resulted in the removal of phenols below discharge limits and a substantial 
toxicity drop. However, only marginal COD removal was achieved, thereby indicating that treatment selectively targeted phenols in the waste. PEG was not effective as a protective additive in this waste matrix but results indicated that the condensate already contained species that protect the enzyme from inactivation by reaction products. These species were identified as lignin derivatives. Unexpectedly, peroxidase has consistently performed more efficiently in the foundry, petroleum, and Kraft mill wastes than when used to treat pure solutions of aqueous phenols (Wagner and Nicell, 2000; 2001). However, due to the fragility of most enzymes, this is not expected to be the case for many of the enzymes that have been identified as candidates for environmental applications.

\section{Reaction Products}

The main objective of using enzymes in waste treatment is to act on specific pollutants to transform them into innocuous products. Complete mineralization of contaminants is preferred to other transformations but the production of ammonia and formate from cyanide wastes or the conversion of organophosphate pesticides to easily removable products is also acceptable. However, it must be recognized that in certain cases the products of enzymatic action might be more toxic than the parent compounds, thereby defeating the purpose of enzyme use. Ultimately, it is desirable that the reaction products be less toxic or more biodegradable than the original pollutant, or otherwise more amenable to subsequent treatment. However, no single enzyme can be expected to catalyze very extensive transformations of pollutants and, thus, reaction products are likely to retain some of the characteristics of the parent compound (Aitken, 1993). Therefore, it is necessary to characterize reaction products to assess their impact on downstream processes or on the environment into which they are released. Unfortunately, only a few studies have been done to investigate this matter mainly because of the difficulty of identifying the products of enzymatic reactions and the difficult task of assessing their toxicity. For example, some studies have been performed to examine the toxicity of trace quantities of soluble products that remain after the treatment of phenols with peroxidases. Ghioureliotis and Nicell (1999) demonstrated that there is a gradual accumulation of dissolved toxic soluble products during the treatment of phenol. However, these products could be easily removed using activated carbon as a polishing step. In addition, when mixtures of phenols were treated in combination, the resulting toxicity was significantly lower (Ghioureliotis and Nicell, 2000). This is of practical importance given that many wastewaters are contaminated with a variety of phenols. Aitken et al (1994) and Massey et al (1994) have studied the mutagenicity of reaction products resulting from the oxidation of phenols by enzymes. Massey et al (1994) tested 17 reaction products from the oxidation of phenols by chloroperoxidase, horseradish peroxidase, lignin peroxidase and polyphenol oxidase. They reported that, in general, they did not observe the formation of mutagenic products. However, the oxidation of nitrophenol by lignin peroxidase did result in the formation of mutagenic products. Chloroperoxidase might also form some toxic products in the presence of chloride ions because of its capacity to oxidize the latter (Aitken et al, 1994). Hence, it would be 
advisable to use chloroperoxidase only in the absence of chloride ions. Ikehata and Nicell (2000) demonstrated that all solutions of phenols and chlorophenols that were treated with tyrosinase followed by the addition of chitosan had substantially lower toxicities. These results and those of Massey et al (1994) are encouraging but similar studies should be performed for other enzymes considered for use in waste treatment.

\section{Disposal of Solid Residues}

One of the common products of waste treatment processes is solid waste that must be disposed of safely. Enzymatic treatment is no exception. For example, while enzymatic treatment may not produce as large a quantity of solid products as biological treatment, some solid residues may remain at the end of the reaction; e.g., the polymer precipitates formed while treating phenols with peroxidases, spent adsorbents such as talc, chitin or activated carbon that are used to eliminate the soluble products of enzymatic reactions, residues of plant materials such as raw soybean hulls when they are used in place of purified enzymes during treatment, or metal complexes formed when using phosphatase to treat heavy metals. Perhaps, the polymers and adsorbents could be incinerated to recover some energy if the emission of dangerous combustion by-products can be controlled or prevented. The residues of plant materials could potentially be composted and used as soil conditioners, provided pollutants do not leach from them at substantial rates. The heavy metal complexes might be more difficult to handle because of potential leaching from landfills. However, attempts at recuperating the metals for industrial reuse might prove feasible and could alleviate the problem. To-date, none of these disposal problems has been addressed adequately.

\section{CONCLUSION}

A variety of enzymes from plants and microorganisms have been reported to play an important role in an array of waste treatment applications. Enzymes can act on specific recalcitrant pollutants to remove them by precipitation or transformation to other innocuous products. They also can change the characteristics of a given waste to render it more amenable to treatment or to aid in converting waste material to valueadded products. Overall, there appears to be a great potential for enzymes in a large number of waste treatment areas. Particularly notable is the possibility of using enzymes to convert wastes from the food processing industry, the pulp and paper industry or simply municipal solid wastes. This has the double advantage of reducing the amount of waste materials that must be discarded, while at the same time creating valuable products such as fuels, feeds and commodity chemicals. However, before their full potential can be realized, some major issues remain to be addressed. These include, but are not limited to, development of low-cost enzymes in quantities that are required at an industrial scale, demonstration of the feasibility of the enzymes under conditions experienced during wastewater treatment, characterization of reaction products and assessment of their impact on downstream processes or the environment, and identification of methods for disposal of solid residues. 


\section{REFERENCES}

Adler, P.R., Arora, R., El Ghaouth, A., Glenn D.M. and Solar J.M., "Bioremediation of Phenolic Compounds from Water with Plant Root Surface Peroxidases”, Journal of Environmental Quality, Vol. 23, 1994, pp. 1113-1117.

Aitken, M.D., "Waste Treatment Applications of Enzymes: opportunities and obstacles", The Chemical Engineering Journal, Vol. 52, 1993, pp. B49-B58.

Aitken, M.D. and Irvine, R.L., "Stability Testing of Ligninase and Mn-peroxidase from Phanerochaete Chrysosporium", Biotechnology and Bioengineering, Vol. 34, 1989, pp. 1251-1260.

Aitken, M.D., Massey, I.J., Chen, T. and Heck, P.E., "Characterization of Reaction Products from the Enzyme Catalyzed Oxidation of Phenolic Pollutants", Water Research, Vol. 28, 1994, pp. 1879-1889.

Aitken, M.D., Venkatadri, R. and Irvine, R.L., "Oxidation of Phenolic Pollutants by a Lignin Degrading Enzyme from the White-Rot Fungus Phanerochaete chrysosporium”, Water Research, Vol. 23, 1989, pp. 443-450.

Al-Kassim, L., Taylor, K.E., Nicell, J.A., Bewtra, J.K. and Biswas, N., "Enzymatic Removal of Selected Aromatic Contaminants from Wastewater by a Fungal Peroxidase from Coprinus macrorhizus in batch reactors", Journal of Chemical Technology and Biotechnology, Vol. 61, 1994, pp. 179-182.

Anazia, I. and Misra, M., "Enzymatic Dewatering of Florida Phosphate Slimes", Minerals and Metallurgical Processes, Vol. 6, No. 2, 1989, pp. 93-95.

Arseguel, D. and Baboulène, M., "Removal of Phenol from Coupling of Talc and Peroxidase: Application for Depollution of Wastewater Containing Phenolic Compounds", Journal of Chemical Technology and Biotechnology, Vol. 61, 1994, pp. 331-335.

Atlow, S.C., Bonadonna-Aparo, L. and Klibanov A.M., "Dephenolization of industrial wastewaters catalyzed by polyphenol oxidase", Biotechnology and Bioengineering, Vol. 26, 1984, pp. 599-603.

Bajza, Z., and Markovic, I., "Influence of Enzyme Concentration on Leather Waste Hydrolysis Kinetics", Journal of the Society of Leather Technologists and Chemists", Vol. 83, No. 3, 1999, pp. 172-176.

Basheer, S., Kut, Ö.M., Prenosil, J.E. and Bourne, J.R., "Kinetics of Enzymatic Degradation of Cyanide", Biotechnology and Bioengineering, Vol. 41, 1992, pp. 465 473. 
Basheer, S., Kut, Ö.M., Prenosil, J.E. and Bourne, J.R., "Development of an Enzyme Membrane Reactor for Treatment of Cyanide-Containing Wastewaters from the Food Industry", Biotechnology and Bioengineering, Vol. 39, 1993, pp. 629-635.

Blasheck, H.P., "Approaches to Making the Food Processing Industry more Environmentally Friendly", Trends in Food Science and Technology, Vol. 3, 1992, 107-110.

Bodzek, M., Bohdziewicz, J. and Kowalska, M., "Preparation of MembraneImmobilised Enzymes for Phenol Decomposition", Journal of Chemical Technology and Biotechnology, Vol. 61, 1994, pp. 231-239.

Bollag, J.-M., "Decontaminating Soil with Enzymes", Environmental Science and Technology, Vol. 26, 1992, pp. 1876-1881.

Bollag, J.-M., Shuttleworth, K.L. and Anderson, D.H., "Laccase-Mediated Detoxification of Phenolic Compounds", Applied Environmental Microbiology, Vol. 54, 1988, pp. 3086-3091.

Brennan, M. B., "New Age Paper and Textiles: Fungi, Enzymes and Closed-Loop Catalysis Offer Environmental, Economic Gains in Manufacturing and Recycling", C\&EN, March 23, 1998, pp. 39-47.

Caldwell, S.R. and Raushel, F.M., "Detoxification of Organophosphate Pesticides Using an Immobilized Phosphotriesterase from Pseudomonas diminuta", Biotechnology and Bioengineering, Vol. 37, 1991, pp. 103-109.

Clanet, M., Durand, H. and Tiraby, G., "Enzymatic Saccharification of Municipal Wastes", Biotechnology and Bioengineering, 32, 1988, pp. 930-934.

Coleman, R., "Biodegradable Plastics from Potato Waste Double Savings to Environment", Agricultural Engineering, Vol. 71, No. 6, 1990, pp. 20-22.

Cooper, V.A. and Nicell, J.A., "Removal of Phenols from a Foundry Wastewater using Horseradish Peroxidase”, Water Research, Vol. 30, No. 4, 1996, pp. 954-964.

Coppella, S.J., DelaCruz, N., Payne, G.F., Pogell, B.M., Speedie, M.K., Karns, J.S., Sybert, E.M. and Connor, M.A., "Genetic Engineering Approach to Toxic Waste Management: Case Study for Organophosphate Waste Treatment", Biotechnology Progress, Vol. 6, 1990, pp. 76-81.

Cornwell, R.L., Tinland-Butez, M.-F., Tardone, P.J., Cabasso, I. and Hammel, K.E., "Lignin Degradation and Lignin Peroxidase Production in Cultures of Phanerochaete chrysosporium Immobilized on Porous Ceramic Supports", Enzyme and Microbial 
Technology, Vol. 12, 1990, pp. 916-920.

Cosio, I.G., Fisher, R.A. and Carroad, P.A., "Bioconversion of Shellfish Chitin Waste: Waste Pretreatment, Enzyme Production, Process Design and Economic Analysis", Journal of Food Science, Vol. 47, 1982, pp. 901-905.

Coughlan, M.P., "Enzymic Hydrolysis of Cellulose: An Overview”, Bioresource Technology, Vol. 39, 1992, pp. 107-115.

Dalev, P.G., "Utilisation Of Waste Feathers from Poultry Slaughter for Production of a Protein Concentrate", Bioresource Technology, Vol. 48, 1994, pp. 265-267.

Davies, M. A personal communication. Director, Tobacco and Health Research Institute, University of Kentucky, May, 1998.

Dec, J. and Bollag, J.-M., "Use of Plant Material for the Decontamination of Water Polluted with Phenols", Biotechnology and Bioengineering, Vol. 44, 1994, pp. 11321139.

Duff, S.J., Moritz, J.W. and Andersen, K.L., "Simultaneous Hydrolysis and Fermentation of Pulp Mill Primary Clarifier Sludge", Canadian Journal of Chemical Engineering, Vol. 72, 1994, pp. 1013-1020.

Duff, S.J., Moritz, J.W. and Casavant, T.E., "Effect of Surfactant and Particle Size Reduction on Hydrolysis of Deinking Dludge and Nonrecyclable Newsprint", Biotechnology and Bioengineering, Vol. 45, 1995, pp. 239-244.

Ferrer, I., Dezotti, M. and Durán, N., "Decolorization of Kraft Effluent by Free and Immobilized Lignin Peroxidases and Horseradish Peroxidase", Biotechnology Letters, Vol. 13, 1991, pp. 577-582.

Flock, C. Bassi A., Gijzen M., "Removal of Aqueous Phenol and 2-Chlorophenol with Purified Soybean Peroxidase and Raw Soybean Hulls", Journal of Chemical Technology and Biotechnology, Vol. 74, No. 4, 1999, pp. 303-309.

Ghioureliotis, M. and Nicell, J.A., "Assessment of Soluble Products of PeroxidaseCatalyzed Polymerization of Aqueous Phenol", Enyzme and Microbial Technology, Vol. 25, 1999, pp. 185-193.

Ghioureliotis, M. and Nicell, J.A., "Toxicity of Soluble Products from the PeroxidaseCatalyzed Polymerization of Substituted Phenolic Compounds", Journal of Chemical Technology and Biotechnology, Vol. 75, 2000, pp. 98-106.

Grasshof, A., "Laboratory Studies on Cleaning Milk-Heaters with Enzymatic Cleaning Solutions", Kieler Milchwirtschaftliche Forschungsberichte, Vol. 51, No. 4, 1999, pp. 
295-318.

Hakulinen, R. "The Use of Enzymes for Wastewater Treatment in the Pulp and Paper Industry - A New Possibility”, Water Science and Technology, Vol. 20, No. 1, 1988, pp. 251-262.

Hammel, K.E., "Organopollutant Degradation by Ligninolyic Fungi”, Enzyme and Microbial Technology, Vol. 11, 1989, pp. 776-777.

Huh, G.H., Yun, B.W., Lee, H.S., Jo, J.K., and Kwak, S.S., "Overproduction of Sweet Potato Peroxidases in Transgenic Tobacco Plants", Phytochemistry, Vol. 47, No. 5, 1998, pp. 695-700.

Ikehata, K. and Nicell, J.A., "Assessment of the Products of Tyrosinase-Catalyzed Oxidation of Phenols", Process Biotechnology Vol. 16, No. 4, 2000, pp. 533-540.

Khan, L.I. and Sarker, M., "Enzyme Enhanced Stabilization of Soil and Fly Ash.” In "Fly ash for Soil Improvement", Proceedings of the 1993 ASCE Annual Convention, Dallas, Texas, 1993, pp. 43-50.

Kimura, C.C, Garcia, E.E., Martins, A.C., and Nozaki, J., "Chemical and Enzymatic Hydrolysis of Chrome Shavings", Anales de la Asociacion Quimica Argentina, Vol. 87, No.3/4, 1999, pp. 97-103.

Kirk, T.K. and Yang, H.H., "Partial Delignification of Unbleached Kraft Pulp with Ligninolytic Fungi”, Biotechnology Letters, Vol. 1, 1979, pp. 347-352.

Klibanov, A.M., "Enzymatic Removal of Hazardous Pollutants in Aqueous Effluents", Enzyme Engineering, Vol. 6, 1982, pp. 319-323.

Klibanov, A.M., "Peroxidase-Catalyzed Removal of Phenols from Coal-Conversion Waste Waters", Science, Vol. 221, 1983, pp. 259-260.

Klibanov, A.M., Alberti, B.N., Morris, E.D. and Felshin, L.M., "Enzymatic Removal of Toxic Phenols and Anilines from Waste Waters", Journal of Applied Biochemistry, Vol. 2, 1980, pp. 414-421.

Klibanov, A.M. and Morris, E.D., "Horseradish Peroxidase for the Removal of Carcinogenic Aromatic Amines from Water", Enzyme and Microbial Technology, Vol. 3, 1981, pp. 119-122.

Lagerkvist, A. and Chen, H., "Control of Two-Step Anaerobic Degradation of Municipal Solid Waste (MSW) by Enzyme Addition. Water Science and Technology, Vol. 27, 1993, pp. 47-56. 
Lankinen, V.P., Inkeröinen, M.M., Pellinen, J. and Hatakka, A.I., "The Onset of Lignin-Modifying Enzymes, Decrease of AOX and Color Removal by White-Rot Fungi Grown on Bleach Plant Effluents", Water Science and Technology, Vol. 24, No. 3-4, 1991, pp. 189-198.

Lige, B., Ma, S., Zhao, D., Van Huyslee, R.B., "Cationic Plant Peroxidase: Expression and Characterization in Transgenic Tobacco and Purification of the Histidine-Tagged Protein”, Plant Science, Vol. 136, No. 2, 1998, pp. 159-168.

Macaskie, L.E. and Dean, A.C.R., "Cadmium Accumulation by a Citrobacter sp.", Journal of General Microbiology, Vol. 130, 1984, pp. 53-62.

Macaskie, L.E., Wates, J.M.and Dean, A.C.R., "Cadmium Accumulation by a Citrobacter sp. Immobilized on Gel and Solid Supports: Applicability to the Treatment of Liquid Wastes Containing Heavy Metal Cations", Biotechnology and Bioengineering, Vol. 30, 1987, pp. 66-73.

Massey, I.J., Aitken, M.D., Ball, L.M. and Heck, P.E., "Mutagenicity Screening of Reaction Products from the Enzyme-Catalyzed Oxidation of Phenolic Pollutants", Environmental Toxicology and Chemistry, Vol. 11, 1994, pp. 1743-1752.

Milstein, O., Haars, A., Majcherczyk, A., Trojanowski, J., Tautz, D., Zanker, H. and Hüttermann A., "Removal of Chlorophenols and Chlorolognins from Bleaching Effluent by Combined Chemical and Biological Treatment", Water Science and Technology, Vol. 20, No. 1, 1988, pp. 161-170.

Munnecke, D.M., "Properties of an Immobilized Pesticide-Hydrolyzing Enzyme", Applied Environmental Microbiology, Vol. 33, 1977, pp. 503-507.

Munnecke, D. M., "Detoxification of Pesticides Using Soluble or Immobilised Enzymes", Process Biochemistry, Vol. 13, 1978, pp. 14-17.

Nakamoto, S. and Machida, N., "Phenol Removal from Aqueous Solutions by Peroxidase-Catalyzed Reaction Using Additives", Water Research, Vol. 26, 1992, pp. 49-54.

Nazly, N., Knowles, C.J., Beardsmore, A.J., Naylor, W.T. and Corcoran, E.G., "Detoxification of Cyanide by Immobilised Fungi", Journal of Chemical Technology and Biotechnology, Vol. 33B, 1983, pp. 119-126.

Nicell, J.A., Bewtra, J.K., Biswas, N, St. Pierre, C. and Taylor, K.E., "Enzyme Catalyzed Polymerization and Precipitation of Aromatic Compounds from Aqueous Solution", Canadian Journal of Civil Engineering, Vol. 20, 1993, pp. 725-735.

Nicell, J.A., Bewtra, J.K., Biswas, N. and Taylor, K.E., "Reactor Development for 
Peroxidase Catalyzed Polymerization and Precipitation of Phenols from Wastewater", Water Research, Vol. 27, No. 11, 1993, pp. 1629-1639.

Pellinen, J., Yin, C.-F., Joyce, T.W. and Chang, H.-M., "Treatment of Chlorine Bleaching Effluent Wsing a White-Rot Fungus", Journal of Biotechnology, Vol. 8, 1988, pp. 67-76.

Pradham, A.A. and Levine, A.D., "Experimental Evaluation of Microbial Metal Uptake by Individual Components of a Microbial Biosorption System", Water Science and Technology, Vol. 26, No. 9-11, 1992, pp. 2145-2148.

Rivers, D.B. and Emert, G.H., "Factors Affecting the Enzymatic Hydrolysis of Municipal-Solid-Waste Components", Biotechnology and Bioengineering, Vol. 3, 1988, pp. 278-281.

Royer, G., Yerushalmi, L., Rouleau, D. and Desrochers M., "Continuous Decolorization of Bleached Kraft Effluents by Coriolus Versicolor on the Form of Pellets. Journal of Industrial Microbiology, Vol. 7, 1991, pp. 269-278.

Schmidt, R.L. and T.W. Joyce, T.W., “An Enzymatic Pretreatment to Enhance the Lime Precipitability of Pulp Mill Effluents", Internal Report, Institute of Paper Chemistry, Appleton, WI, 1981.

Shoemaker, S., "The Use of Enzymes for Waste Management in the Food Industry", In "Biotechnology in Food Processing", (Harlander S.K. and Labuza T.P. editors), Nayes Publications, 1986, pp. 259-267.

Smith, J.M., Payne, G.F and Lumpkin, J.A., "Enzyme-Based Strategy for Toxic Waste Treatment and Waste Minimization”, Biotechnology and Bioengineering, Vol. 39, 1982, pp. 741-752.

Sun, W.-Q., Payne, G.F., Moas, M., Chu, J.H. and Wallace, K.K., "Tyrosinase Reaction/Chitosan Adsorption for Removing Phenols from Wastewater", Biotechnology Progress, Vol. 8, 1992, pp. 179-186.

Taya, M., Yoyama, A., Nomura, R., Kondo, O., Matsui, C., and Kobayashi, T., "Production of Peroxidase Hairy Root Cells in a Two Step Culture System", Journal of Fermentation Bioengineering, Vol. 67, 1989, pp. 31-34.

Thomas, L., Jungschaffer, G. and Sprössler, B., "Improved Sludge Dewatering by Enzymatic Treatment. Water Science and Technology, Vol. 28, No. 1, 1993, pp. 189192.

Thomas, O.R.T. and White, G.F., "Immobilization of the Surfactant-Degrading Bacterium Pseudomonas C12B in Polyacrylamide Gel. III. Biodegradation Specificity 
for Raw Surfactants and Industrial Wastes", Enzyme and Microbial Technology, Vol. 13, 1991, pp. 338-343.

Venkatadri, R. and Irvine, R.L., "Cultivation of Phanerochaete chrysosporium and Production of Lignin Peroxidase in Novel Biofilm Reactor Systems: Hollow Fiber Reactor and Silicone Membrane Reactor. Water Research, Vol. 27, 1993, pp. 591596.

Venugopal, V., Alur, M.D. and Nerkar D.P., "Solubilization of Fish Proteins Using Immobilized Microbial Cells", Biotechnology and Bioengineering, Vol. 33, 1989, pp. 1098-1103.

Wada, S., Ichikawa, H. and Tatsumi, K., "Removal of Phenols with Tyrosinase Immobilized on Magnetite", Water Science and Technology, Vol. 26, No. 9-11, 1992, pp. 2057-2059.

Wada, S., Ichikawa, H. and Tatsumi, K., "Removal of Phenols from Wastewater by Soluble and Immobilized Tyrosinase", Biotechnology and Bioengineering, Vol. 42, 1993, pp. 854-858.

Wagner, M. and Nicell, J.A., "Peroxidase-Catalyzed Removal of Phenols from a Petroleum Refinery Wastewater", Water Science and Technology, 2000 (in press).

Wagner, M. and Nicell, J.A., "Treatment of a Foul Condensate from Kraft Pulping with Horseradish Peroxidase and Hydrogen Peroxide", Water Research, Vol. 35, No. 2, 2001, pp. 485-495.

Worley, J., "UK's Tobacco and Health Institute Branching Out: Tobacco as a "Factory" to Grow New Products", Odyssey: The Magazine of the University of Kentucky, Spring, 1998, pp. 3-7.

Wright, H. and Nicell, J.A., "Characterization of Soybean Peroxidase for the Treatment of Aqueous Phenols", Bioresource Technology, Vol. 70, 1999, pp. 69-79. 